\title{
Erratum to: Re-visiting BMI as an Enabler of Strategic Intent and Organizational Resilience, Robustness, and Remunerativeness
}

\author{
Elias G. Carayannis ${ }^{1}$ - Evangelos Grigoroudis ${ }^{2}$ • \\ Dimitra Stamati ${ }^{2}$
}

\section{Erratum to: J Knowl Econ DOI 10.1007/s13132-017-0471-3}

The original version of this article unfortunately contained a mistake. The name of Vangelis Grigoroudis should be corrected to Evangelos Grigoroudis. The correct name is now presented above. 